\title{
Review Article \\ Regulation of p63 Protein Stability via Ubiquitin-Proteasome Pathway
}

\author{
Chenghua Li and Zhi-Xiong Xiao \\ Center of Growth, Metabolism and Aging, Key Laboratory of Biological Resources and Ecological Environment of Ministry of Education, \\ College of Life Sciences, Sichuan University, Chengdu 610064, China
}

Correspondence should be addressed to Zhi-Xiong Xiao; bmc605@hotmail.com

Received 25 December 2013; Revised 10 March 2014; Accepted 28 March 2014; Published 15 April 2014

Academic Editor: Xin-yuan Guan

Copyright (C) 2014 C. Li and Z.-X. Xiao. This is an open access article distributed under the Creative Commons Attribution License, which permits unrestricted use, distribution, and reproduction in any medium, provided the original work is properly cited.

The p53-related p63 gene encodes multiple protein isoforms, which are involved in a variety of biological activities. p63 protein stability is mainly regulated by the ubiquitin-dependent proteasomal degradation pathway. Several ubiquitin E3 ligases have been identified and some protein kinases as well as other kinds of proteins are involved in regulation of p63 protein stability. These regulators are responsive to diverse extracellular signaling, resulting in changes of the p63 protein levels and impacting different biological processes.

\section{Introduction}

The p53 family member, p63 gene, is located on human chromosome 3q27-29. In contrast to the high frequency of p53 mutations in cancers, p63 gene is rarely mutated $[1,2]$. However, up to $60 \%$ of squamous cell carcinomas show elevated p63 protein levels [3]. In addition, mutations in the p63 gene have been linked to several human developmental diseases. A vast body of evidence demonstrates that p63 are key transcription factors involved in cell growth, proliferation, apoptosis, and differentiation and play an essential role in epithelial stem cell biology and development [4-8]. Due to their key roles in a variety of essential biological processes, abundances of p 63 proteins are tightly controlled. Ubiquitin-dependent proteasomal degradation is the most important way to eliminate cellular p63 proteins. Some important regulators, including ubiquitin E3 ligases, kinases, and proteins in other classes, have been reported to control p63 degradation. Multiple extracellular signalings, such as growth factor signaling and genotoxic stress, impact these regulators, which in turn modulate protein stability of p63 $[9,10]$. This review is aimed at understanding the molecular mechanisms, by which p63 protein stability is regulated, and the players in modulating ubiquitin-dependent proteasomal degradation of $\mathrm{p} 63$ proteins.

\section{Isoforms of p63 and Their Biological Functions}

The p63 gene consists of 15 exons that can be transcribed from two transcriptional start sites. The transcript from $5^{\prime}$ promoter of p63 gene proceeding to the first exon encodes TA isotypes of $\mathrm{p} 63$ proteins with the full transactivation domain (TAD) homologues to that of p53 on the $\mathrm{N}$-terminus, while transcript from the cryptic $3^{\prime}$ intronic promoter gives rise to $\Delta \mathrm{N}$ isoforms containing a different and weaker domain capable of transactivation. Both TA and $\Delta \mathrm{N}$ isotypes can undergo alternative splicing to generate different carboxytermini, including $\alpha, \beta, \gamma, \delta$, and $\varepsilon$. Thus, p63 gene can encode at least 10 different p63 isoforms, $\mathrm{TA}(\alpha \sim \varepsilon)$ and $\Delta \mathrm{N}(\alpha \sim \varepsilon)$ (as depicted in Figure 1). Each p63 isoform possesses a DNAbinding domain (DBD) and an oligomerization domain (OLD), both of which are highly homologous to those of p53 protein. Among these p63 isoforms, p63 $\alpha$ contains a fulllength C-terminus consisting of a sterile alpha motif (SAM) for protein interaction and a transinhibitory domain (TID), whereas other isoforms have truncated C-termini due to alternative splicing [11-13]. Evidence from human genetics and animal models reveals that p63 proteins play crucial roles in stratification of squamous epithelia, differentiation of mature keratinocytes, and epidermal morphogenesis during 


\begin{tabular}{rl|l|lll|l|l|l|l|} 
TAp63 $\alpha$ & TAD & & & DBD & & OLD & & SAM & TID \\
\hline 1 & 98 & 182 & & 360 & 393 & 432 & 505 & 579 & 680
\end{tabular}
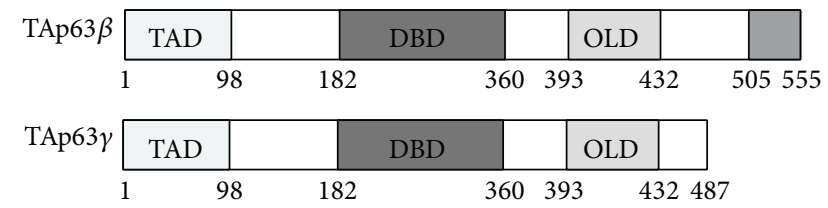

\begin{tabular}{rl|l|l|l|l|l|l|}
$\operatorname{TAp} 63 \delta$ & TAD & & DBD & & OLD & \\
\hline 1 & 98 & 182 & & 360 & 393 & 432 & 510
\end{tabular}
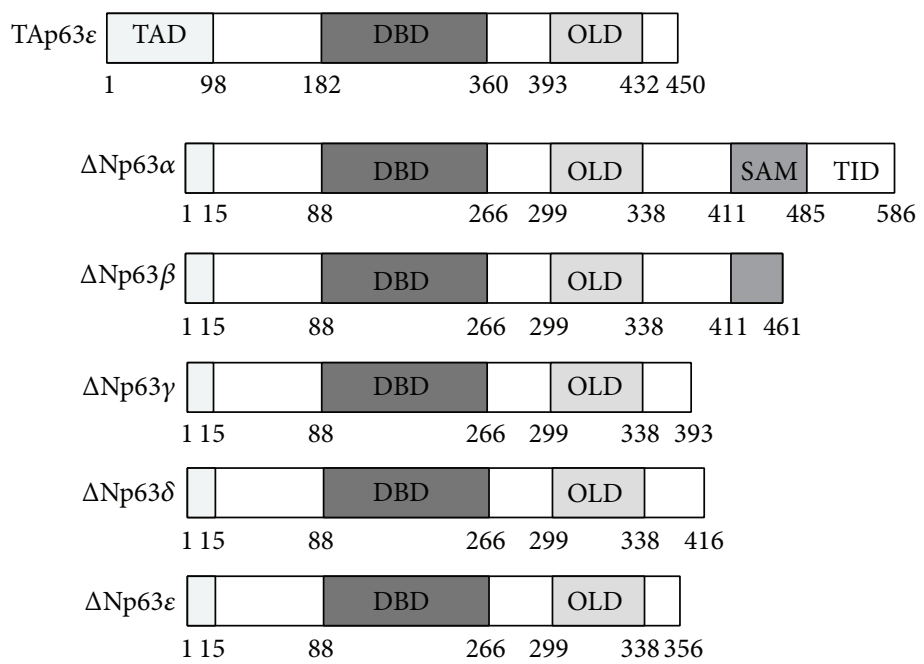

FIGURE 1: Schematic presentation of p63 isoforms. TAD: transactivation domain; DBD: DNA-binding domain; OLD: oligomerization domain; SAM: sterile alpha motif; TID: transinhibitory domain.

development $[14,15]$. Multiple p63 isotypes (both TA and $\Delta \mathrm{N}$ isoforms) are expressed in keratinocytes and they are differentially modulated during differentiation $[16,17]$.

Endogenous TAp63 proteins are barely detectable in embryos and adult (except in oocytes), presumably because of their low expression or rapid degradation as well as lack of antibodies able to detect weak expression [18]. It is well supported that, like p53, TAp63 proteins promote cell cycle arrest and apoptotic cell death via activating proapoptotic targets, such as Puma, Bax, and Noxa in somatic cells [1, 19, 20]. In oocytes, TAp63 $\alpha$ expresses at relatively higher levels and functions as a quality control factor in the female germline, upon genotoxic stress [21-23]. TAp63 knockout mice are highly tumor prone and develop metastatic disease, reaffirming the antitumor activities of TAp63 $[5,6]$. Loss of TAp63 also results in premature aging and reduced lifespan in mice $[5,24]$. Recently, increased obesity, insulin resistance, and glucose intolerance were reported in TAp63-null mice [25].

$\Delta \mathrm{Np} 63$, especially $\Delta \mathrm{Np} 63 \alpha$, are predominant p63 isoforms, which are overexpressed in a highly specific manner in the embryonic ectoderm and the basal regenerative compartment of epithelial tissues, such as skin, teeth, and hair [26]. Similar to mice deleted with all p63 isoforms, $\Delta$ Np63-null mice have striking developmental defects including truncated forelimbs, the absence of hind limbs, and a lack of stratified epidermis [27]. In contrast to the strong transactivation function of TAp63 proteins, $\triangle \mathrm{Np} 63$ isoforms were traditionally believed to inhibit p53 members including p53, TAp63, and TAp73 proteins via forming complexes with them or competitive binding to p53-responsive elements. This transcriptional repressor activity enables $\Delta \mathrm{Np} 63 \alpha$ to promote cell proliferation and tumorigenesis under certain circumstances $[4,11,19,28,29]$. According to this model, the fine balance between the TA and $\Delta \mathrm{N}$ isotypes determines the function of p63 proteins. However, mounting evidence reveals that $\triangle$ Np63 has an intrinsic transcriptional activity owing to a second TA domain (TA2). $\Delta$ Np63 $\alpha$ has been shown to regulate the expression of several adhesion molecules, including integrins $(\beta 1, \beta 4$, and $\alpha 6)$ and desmosome protein PERP, as well as MAP kinase phosphatase 3 (MKP3), heat shock protein 70 (HSP70), multidrug resistant gene 1 (MDR-1), and ATM kinase, implicating its functions in cell growth, invasion, survival, drug resistance, and DNA repair $[8,10,30-$ 32].

\section{Properties of p63 Protein Stability}

Due to their potent proapoptotic activities, TAp63 proteins are generally expressed at very low levels, likely owing to the transcriptional regulation. Alternatively, TAp63 proteins are highly labile. It has been documented that the half-life of 
TAp $63 \gamma$ is about 1.5 hours, and an unknown factor may play as a feedback regulator of TAp63 degradation. $\Delta$ Np63 proteins are much more stable than TAp63 [33]. They are found overexpressed in keratinocyte and squamous carcinoma cells and associated with proliferation. It has been shown that while $\Delta$ Np63 undergoes degradation [34], TAp63 accumulates in response to some extrinsic stresses such as actinomycin D, bleomycin etoposide, and UV irradiation [10]. Some intrinsic physiological processes such as cell differentiation are also likely to regulate degradation of p63 proteins $[16,35,36]$.

Although lysosomal degradation may be involved in regulation of p63 abundance, the most important way of p63 degradation is the proteasome-dependent pathway [10]. The stabilities of p63 proteins are modulated by diverse posttranslational modification, such as phosphorylation, ubiquitylation, SUMOylation, and ISGylation, in which various proteins are involved [26, 37-39].

\section{E3 Ligases Targeting p63 for Proteasomal-Mediated Degradation}

As the primary pathway of p63 protein degradation, ubiquitin-dependent proteasomal degradation of $\mathrm{p} 63$ proteins was reported by several laboratories. E3 ligase-mediated ubiquitylation is the essential step for proteasomal degradation of a specific protein. Up to now, several E3 ligases for p63 proteins have been identified (as listed in Table 1).

4.1. Nedd4. Nedd4 is the first identified E3 ligase for p63. Using a yeast-two-hybrid screening system, Bakkers et al. found that two modifying enzymes, the E3 ubiquitin ligase Nedd4 and the SUMO-conjugating enzyme Ubc9, bind to distinct sites in the unique $\mathrm{C}$-terminal region of $\Delta \mathrm{Np} 63 \alpha$. These physical interactions lead to ubiquitylation and SUMOylation of $\Delta \mathrm{Np} 63 \alpha$, resulting in vulnerability of $\Delta \mathrm{Np} 63 \alpha$ to proteasomal degradation [36]. In zebrafish embryos, $\Delta \mathrm{Np} 63 \alpha$ are expressed at a high level on the dorsal side, due to the restricted expression of $u b c 9.1$ and nedd4 in this region [36]. However, how does the Ubc9-mediated SUMOylation of Lys582 destabilize $\Delta \mathrm{Np} 63 \alpha$ remains unknown. In addition, whether TAp63 $\alpha$, which shares the same C-terminus with $\Delta \mathrm{Np} 63 \alpha$, is modulated by Nedd 4 and Ubc9 remains to be investigated. It was recently reported that $\Delta \mathrm{Np} 63 \alpha$ can transcriptionally repress Nedd 4 [40], suggesting that downregulation of Nedd 4 may function as a feedforward pathway to increase $\Delta \mathrm{Np} 63 \alpha$ intracellular concentration under certain circumstances.

4.2. Itch. Itch is Nedd4-like ubiquitin E3 ligase found to target p63 for ubiquitin-mediated proteasomal degradation. Work from Melino's group found that Itch directly binds to the PPPY motif existing in the SAM domain of p63 $\alpha$. This physical interaction leads to ubiquitylation of either TA- or $\Delta \mathrm{N}-\mathrm{p} 63 \alpha$ isoforms, consequently promoting their proteasomal degradation. A Y $\rightarrow \mathrm{F}$ substitution in the PPPY motif can abolish the binding of Itch and significantly increases p63 $\alpha$ protein stability. Their data suggest that Itch plays a fundamental role in controlling endogenous p63 protein levels and regulating p63-mediated physiological functions, particularly in the epidermis and keratinocytes [26]. This is similar to the case of p73, which is also ubiquitylated and targeted to degradation by Itch through PPPY-Itch interaction [41]. And this is also consistent with cases of p63 degradation mediated by Nedd 4 and WWP1, which both are analogues of Itch and bind to PPPY motif of p63 [36, 42].

Nevertheless, Calabro group found that Itch bound to a different region of p63, the region encompassing aminoacids 109 to 120 of TAp63 (corresponding to amino acids 15 to 26 of $\Delta \mathrm{Np} 63 \alpha$ ). This association between Itch and $\mathrm{N}$-termini of p63 promotes degradation of all p63 isoforms, including both TA- and $\Delta \mathrm{N}$-isotypes [37].

4.3. WWP1. Li et al. found that WWP1, the homologue of Itch, can also bind to the PPPY motif of either TAp63 $\alpha$ or $\Delta \mathrm{Np} 63 \alpha$ and ubiquitinate them in cultured mammalian cells, consequently promoting their proteasomal degradation. Additionally, WWP1 can target endogenous $\Delta \mathrm{Np} 63 \alpha$ proteins for degradation and sensitizes immortalized breast epithelial cells to chemotherapeutic drug doxorubicin-induced apoptosis. Intriguingly, WWP1 can be upregulated at both mRNA and protein levels upon chemotherapeutic drug treatment in a p53-dependent manner [42]. This suggests that $\Delta \mathrm{Np} 63 \alpha$, which is well documented to confer cells to resistance to DNA damage agent-mediated apoptosis [43], may be destabilized by accumulated WWP1 E3 ligase, resulting in cell death, under genotoxic stress.

4.4. Fbw7. Although several groups reported that MDM2, which is a nuclear E3 ubiquitin ligase playing key roles in controlling cellular p53 abundance, cannot individually mediate ubiquitylation of p63 [44-46], Galli et al. found that MDM2 can facilitate ubiquitylation of p63 mediated by another E3 ligase, Fbw7. Upon DNA damage or keratinocytes differentiation, MDM2 binds to the C-terminal SAM region of $\Delta \mathrm{Np} 63 \alpha$ in the nucleus and promotes its translocation to the cytoplasm; then p63 is targeted for degradation by the Fbw7 E3 ubiquitin ligase in the cytosome. In this process, GSK3 kinase activity is required for efficient degradation of p63 by Fbw7 [35].

4.5. Pirh2. Pirh2 (p53-induced RING-H2) is another E3 ligase found to target p63 for degradation. It was recently reported that Pirh2 physically interacts with TAp63 and $\Delta \mathrm{Np} 63$ and targets them for polyubiquitylation and subsequently proteasomal degradation. This Pirh2-mediated posttranscriptional regulation of p63 may modulate keratinocytes differentiation [47]. Arsenic trioxide, a frontline agent for acute promyelocytic leukemia, stimulates Pirh2 expression and consequently promotes proteasomal degradation of $\Delta \mathrm{Np} 63 \alpha$ but not TAp63 $\alpha$ [48]. This is interesting and useful, because $\Delta \mathrm{Np} 63 \alpha$ is generally considered as a potent oncoprotein playing key roles in tumor cell proliferation/survival, whereas TAp63 $\alpha$ is a tumor suppressor with proapoptotic activity. It remains obscure why these two isoforms, which can both be targeted for degradation by Pirh2, have this discrepancy in response to arsenic trioxide treatment. 
TABLE 1: Regulators of p63 protein stability. +: positively regulates p63 protein stability; -: negatively regulates p63 protein stability. *: MDM2 functions as not an E3 ligase here, but a helper to promote translocation of $\Delta \mathrm{Np} 63 \alpha$ to cytoplasm [35].

\begin{tabular}{|c|c|c|c|c|}
\hline Regulators & Stability regulation & p63 isoform & Interaction or modification sites & References \\
\hline \multicolumn{5}{|l|}{ E3 ligases } \\
\hline Nedd 4 & - & $\Delta \mathrm{Np} 63 \alpha$ & PPPY motif in SAM domain & {$[36]$} \\
\hline & - & $\Delta \mathrm{Np} 63 \alpha$ & PPPY motif in SAM domain & {$[26]$} \\
\hline Itch & - & All p63 isoforms & $\begin{array}{l}\text { A region encompassing aminoacids } 109 \text { to } 120 \text { of } \\
\text { TAp63 (aminoacids } 15 \text { to } 26 \text { of } \Delta \text { Np63) }\end{array}$ & {$[37]$} \\
\hline WWP1 & - & 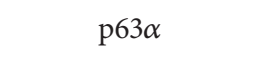 & PPPY motif in SAM domain & {$[42]$} \\
\hline Fbw7 & - & $\Delta \mathrm{Np} 63 \alpha$ & Likely a region encompassing S383 of $\Delta \mathrm{Np} 63 \alpha$ & {$[35]$} \\
\hline Pirh2 & - & TAp63 and $\Delta$ Np63 & & {$[47,48]$} \\
\hline \multicolumn{5}{|l|}{ Kinase } \\
\hline ATM & - & $\Delta \mathrm{Np} 63 \alpha$ & S385 of $\Delta \mathrm{Np} 63 \alpha$ & {$[49]$} \\
\hline $\mathrm{CDK} 2$ & - & $\Delta \mathrm{Np} 63 \alpha$ & T397 of $\Delta \mathrm{Np} 63 \alpha$ & {$[49]$} \\
\hline p70s6K & - & $\Delta \mathrm{Np} 63 \alpha$ & S466 of $\Delta \mathrm{Np} 63 \alpha$ & {$[49]$} \\
\hline \multirow{2}{*}{$\mathrm{IKK} \beta$} & + & TAp63 $\gamma$ & TAD of TAp $63 \gamma$ & {$[51]$} \\
\hline & - & $\Delta \mathrm{Np} 63 \alpha$ & Unknown & $[52]]$ \\
\hline HIPK2 & - & $\Delta \mathrm{Np} 63 \alpha$ & T397 of TAp63 $\gamma$ & {$[55]$} \\
\hline \multirow{2}{*}{ c-Abl } & + & TAp63 & Y149, Y171, and Y289 of TAp63 & {$[22]$} \\
\hline & - & $\Delta \mathrm{Np} 63 \alpha$ & $\mathrm{Y} 55, \mathrm{Y} 137$, and $\mathrm{Y} 308$ of $\Delta \mathrm{Np} 63 \alpha$ & {$[58]$} \\
\hline Plk1 & - & TAp63 & S52 of TAp63 & {$[59]$} \\
\hline p38 & - & $\Delta \mathrm{Np} 63 \alpha$ & Unknown & {$[60]$} \\
\hline GSK3 & - & $\Delta \mathrm{Np} 63 \alpha$ & S383 of $\Delta \mathrm{Np} 63 \alpha$ & {$[35]$} \\
\hline Raf1 & - & $\Delta \mathrm{Np} 63 \alpha$ & S383 or T397 of $\Delta \mathrm{Np} 63 \alpha$ & {$[16]$} \\
\hline \multicolumn{5}{|l|}{ Others } \\
\hline Gadd45a & - & $\Delta \mathrm{Np} 63 \alpha$ & No direct interaction & {$[60]$} \\
\hline p53 & - & $\Delta \mathrm{Np} 63 \alpha$ & DBD of $\Delta \mathrm{Np} 63 \alpha$ & {$[29]$} \\
\hline $\mathrm{MDM}^{*}$ & - & $\Delta \mathrm{Np} 63 \alpha$ & SAM domain & {$[35]$} \\
\hline Cabbles1 & + & TAp63 $\alpha$ & TAD and SAM of TAp $63 \alpha$ & {$[65]$} \\
\hline YAP & + & $\Delta \mathrm{Np} 63 \alpha$ & PPPY motif in SAM domain & {$[58]$} \\
\hline Dlx3 & - & $\Delta \mathrm{Np} 63 \alpha$ & No direct interaction & {$[16]$} \\
\hline Stratifin & - & $\mathrm{p} 63 \alpha$ & RQTISFP motif in TID of $\mathrm{p} 63 \alpha$ & {$[61]$} \\
\hline RACK1 & - & p63 $\alpha$ & C-ter of p $63 \alpha$ & {$[61]$} \\
\hline Stxbp4 & + & $\Delta \mathrm{Np} 63 \alpha$ & PPPY motif in SAM domain & {$[64]$} \\
\hline Ubc9 & - & $\Delta \mathrm{Np} 63 \alpha$ & K582 of $\Delta \mathrm{Np} 63 \alpha$ & {$[36]$} \\
\hline PML & + & p63 $\alpha$ & Unknown & {$[66]$} \\
\hline Pinl & + & $\mathrm{p} 63 \alpha$ & PPPY motif in SAM domain & [67] \\
\hline
\end{tabular}

\section{Kinases Involved in p63 Protein Degradation}

Phosphorylation mediated by diverse kinases plays key roles in protein degradation. So far, several kinases have been reported to be involved in p63 protein stability (as listed in Table 1).

5.1. ATM, CDK2, and $p 70 s 6 K$. Sidransky group found that kinases including ATM, CDK2, and p70s6K can phosphorylate $\Delta \mathrm{Np} 63 \alpha$ in HNSCC (head and neck squamous cell carcinoma) cells upon DNA damage. Phosphorylation at S385, T397, and S466 mediated by these kinases, respectively, promotes degradation of $\Delta \mathrm{Np} 63 \alpha$ [49]. Given that $\Delta \mathrm{Np} 63 \alpha$ can transcriptionally regulate ATM [50], the latter may function as a feedback regulator via a p53/MDM2-like loop to tightly control protein level of $\Delta \mathrm{Np} 63 \alpha$.

5.2. IKK 3 . TAp63 $\gamma$ exhibits potent proapoptotic activity due to possessing a full-length transactivation domain and lacking a transinhibitory domain. Normally, TAp63 $\gamma$ expresses at very low levels in cells. It was reported that, in response to $\gamma$ radiation or tumor necrosis factor- $\alpha$ (TNF- $\alpha$ ), I $\kappa \mathrm{B}$ kinase $\beta(\operatorname{IKK} \beta)$ is activated and phosphorylates TAp63 $\gamma$ (but not $\Delta \mathrm{Np} 63 \gamma)$ at its $\mathrm{N}$-terminus; this phosphorylation can significantly block ubiquitylation and possible degradation 
of TAp63 $\gamma$ in H1299 and HEK293 cells, resulting in elevated protein levels of cellular TAp63 $\gamma[33,51]$.

On the contrary, Sidransky group found that cytokine- or chemotherapy-induced stimulation of IKK $\beta$ kinase promotes ubiquitin-mediated proteasomal degradation of $\Delta \mathrm{Np} 63 \alpha$ in the human head and neck cancer cell line JHU-022, consequently augmenting transactivation of p53 family-induced genes involved in the cellular response to DNA damage [52]. It is unclear how IKK $\beta$ kinase exhibits opposite effects on stabilities of these two different isoforms. An interpretation is that $\Delta \mathrm{Np} 63 \alpha$ and TAp $63 \gamma$ possess different $\mathrm{C}$-terminus or $\mathrm{N}$-terminus.

5.3. HIPK2. Homeodomain-interacting protein kinase 2 (HIPK2) is an evolutionarily conserved serine/threonine kinase involved in the regulation of gene transcription during development and in cell response to several types of stress. HIPK2 is often activated under diverse genotoxic stimuli, including treatment with ultraviolet, ionizing irradiation, and anticancer drugs such as cisplatin, doxorubicin, and roscovitine $[53,54]$. Lazzari et al. found that HIPK2 phosphorylates $\Delta \mathrm{Np} 63 \alpha$ at T397 residue in response to chemotherapy. This modification promotes proteasomal degradation of $\Delta \mathrm{Np} 63 \alpha$, which is mediated by neither Itch nor MDM2 [55].

5.4. c-Abl. c-Abl (also known as ABL1) is a tyrosine kinase, which can be activated upon DNA damage [56, 57]. Gonfloni et al. recently reported that, in response to cisplatin treatment, c-Abl phosphorylates TAp63 $\alpha$ on Y149, Y171, and Y289 residues, resulting in increased protein stability of TAp63 $\alpha$. This can lead to accumulated TAp $63 \alpha$ proteins and eventually cell death in mouse oocytes [22].

Another group found that c-Abl phosphorylates Y55, $\mathrm{Y} 137$, and $\mathrm{Y} 308$ residues of $\Delta \mathrm{Np} 63 \alpha$ and stabilizes it via inducing its binding to Yes-associated protein (YAP), consequently regulating cell viability in head and neck cancer cells [58]. Since Y149, Y171, and Y289 residues of TAp63 $\alpha$ are different from $\mathrm{Y} 55, \mathrm{Y} 137$, and $\mathrm{Y} 308$ of $\Delta \mathrm{Np} 63 \alpha$, it is interesting why TAp63 $\alpha$ and $\Delta \mathrm{Np} 63 \alpha$ are stabilized by c-Abl in different mechanism. It also remains unclear if other isoforms of $\mathrm{p} 63$ can be regulated by c-Abl, given that these six putative c-Abl phosphorylation sites are included in all of p63 isoforms.

5.5. Other Kinases. In addition to the abovementioned kinases, Plk1 [59], p38 [60], GSK3 [35], and Raf1 [16] kinases may be also involved in proteasome-dependent degradation of p63.

\section{Other Proteins Regulating p63 Protein Stability}

Besides E3 ubiquitin ligases and kinases, several other proteins were found to be related to protein stability of p63 (as listed in Table 1). Most of them function as regulators or cofactors of the abovementioned E3 ligases or kinases to promote or inhibit proteasomal degradation of $\mathrm{p} 63$.
6.1. $p 53$. Ratovitski group found that $\mathrm{p} 53$ can bind to DNAbinding domain of p63 in the absence of DNA and promote p63 degradation through a pathway mediated by caspase-1. Interestingly, this p63 caspase-mediated degradation of p63 resulting from $\mathrm{p} 53$-p63 physical interaction needs no further p63 posttranslational modifications [29].

6.2. Stratifin, RACK1, and Stxbp4. In another work, Ratovitski et al. found that, in response to DNA damage, stratifin binds to the putatively phosphorylated $\Delta \mathrm{Np} 63 \alpha$ protein and regulates its level through nuclear-cytoplasmic trafficking, while scaffold protein RACK1 (receptor for activated C kinase 1) subsequently targets $\Delta \mathrm{Np} 63 \alpha$ into a 26S-dependent proteasomal degradation pathway. Though overexpression of RACK1 dramatically enhances ubiquitylation of $\Delta \mathrm{Np} 63 \alpha$, it needs further confirmation if RACK1 serves as an E3 ligase in this pathway [61].

Since it has been documented that RACK1 can regulate FAK activity [62], it is also possible that RACK1 promotes ubiquitylation via affecting phosphorylation of p63. Notably, it has been reported that stratifin is transcriptionally regulated by $\mathrm{p} 63$ and $\mathrm{p} 53[28,63]$. So this modulation of p63 mediated by stratifin/RACK1 may also form a regulation loop.

Another scaffold protein Stxbp4 was found to counteract this RACK1-dependent degradation pathway to maintain high basal levels of $\triangle \mathrm{Np} 63$ in stratified epithelial cells under normal growth conditions; but in response to DNA damage, Stxbp4 is downregulated, correlating with $\Delta \mathrm{Np} 63 \alpha$ destabilization mediated in part by RACK1 [64].

6.3. Other Proteins. Hildesheim et al. reported that under genotoxic stress Gadd45a mediates activation of p38 MAP kinase and consequently downregulates $\triangle \mathrm{Np} 63 \alpha$ protein [60]. Wang et al. found that Cables1 (CDK5 and Abl enzyme substrate 1) associates with both TAD and SAM regions of TAp $63 \alpha$ to protect TAp63 $\alpha$ from proteasomal degradation [65]. Bernassola et al. found that the promyelocytic leukaemia protein (PML) physically interacts with TAp $63 \alpha$ and $\Delta \mathrm{Np} 63 \alpha$ and increases their protein levels [66]. According to results of Di Costanzo et al., homeodomain protein Dlx3 physically interacts with and activates Raf1 kinase, resulting in enhanced phosphorylation and degradation of $\Delta \mathrm{Np} 63 \alpha$ [16]. As mentioned above, YAP and Ubc9 are also involved in regulation of p63 degradation $[36,58]$. Recently, we found that peptidylprolyl isomerase Pinl inhibits binding of WWP1 E3 ligase to p63 $\alpha$, consequently preventing its proteasomal degradation [67].

\section{Summary and Prospects}

Taken together, current studies reveal that $\mathrm{p} 63$ protein stability is tightly controlled and closely correlated with cell proliferation, cell death, and cell differentiation. Various signalings and stresses can affect p63 protein stability via regulating E3 ligases or activities of diverse kinases. Notably, the same residues or same regions are targeted by different E3 ligases or different signaling. For instance, T397 of $\Delta \mathrm{Np} 63 \alpha$ can be phosphorylated by several kinases, including CDK2, HIPK2, 
and Rafl, consequently promoting degradation of $\Delta \mathrm{Np} 63 \alpha$; three E3 ligase homologues, NEDD4, Itch, and WWP1, target p63 for proteasomal degradation via binding to PPPY motif of $\mathrm{p} 63 \alpha$ and $\mathrm{p} 63 \beta$. Furthermore, the regulation of $\mathrm{p} 63$ protein stability is complex, since the effects of E3 ligases on p63 degradation are modulated by kinases and other regulators. Some of the factors can be transcriptionally regulated by p63, forming some regulation loops. Further investigations are required to clarify the relationships between different regulators in p63 protein stability upon exogenous signaling. Moreover, it is necessary to elucidate how different p63 isotypes are targeted to degradation during cell differentiation, since a switch in expression of different $\mathrm{p} 63$ isoforms is pivotal in this process [68].

On the other hand, it would be important to investigate key regulators for p63 degradation that are responsible for p63-related human developmental diseases. Like the paradigm of promising anticancer drug Nutlin-3, which can stabilize p53 via disrupting its association with MDM2 [69], it would be interesting to develop potent inhibitors targeting E3 ligases in order to stabilize TAp63 tumor suppressors or to destabilize $\triangle \mathrm{Np} 63$ oncoproteins.

\section{Conflict of Interests}

The authors declare that there is no conflict of interests regarding the publication of this paper.

\section{Acknowledgments}

This work was supported in part by the National Natural Science Foundation of China (no. 31171362 to Z. Xiao and no. 31100982 to C. Li) and Research Foundation for the Doctoral Program, Ministry of Education of China (no. 2011018120082 to C. $\mathrm{Li})$.

\section{References}

[1] M. Osada, M. Ohba, C. Kawahara et al., "Cloning and functional analysis of human p51, which structurally and functionally resembles p53," Nature Medicine, vol. 4, no. 7, pp. 839-843, 1998.

[2] B. Trink, K. Okami, L. Wu, V. Sriuranpong, J. Jen, and D. Sidransky, "A new human p53 homologue," Nature Medicine, vol. 4, no. 7, pp. 747-748, 1998.

[3] K. Hibi, B. Trink, M. Patturajan et al., "AIS is an oncogene amplified in squamous cell carcinoma," Proceedings of the National Academy of Sciences of the United States of America, vol. 97, no. 10, pp. 5462-5467, 2000.

[4] M. Senoo, F. Pinto, C. P. Crum, and F. McKeon, "p63 is essential for the proliferative potential of stem cells in stratified epithelia," Cell, vol. 129, no. 3, pp. 523-536, 2007.

[5] X. Guo, W. M. Keyes, C. Papazoglu et al., “TAp63 induces senescence and suppresses tumorigenesis in vivo," Nature cell biology, vol. 11, no. 12, pp. 1451-1457, 2009.

[6] X. Su, D. Chakravarti, M. S. Cho et al., "TAp63 suppresses metastasis through coordinate regulation of Dicer and miRNAs," Nature, vol. 467, no. 7318, pp. 986-990, 2010.

[7] W. M. Keyes, M. Pecoraro, V. Aranda et al., " $\Delta$ np63 $\alpha$ is an oncogene that targets chromatin remodeler Lsh to drive skin stem cell proliferation and tumorigenesis," Cell Stem Cell, vol. 8, no. 2, pp. 164-176, 2011.

[8] D. K. Carroll, J. S. Carroll, C.-O. Leong et al., "p63 regulates an adhesion programme and cell survival in epithelial cells," Nature Cell Biology, vol. 8, no. 6, pp. 551-561, 2006.

[9] C. Maisse, P. Guerrieri, and G. Melino, "p73 and p63 protein stability: the way to regulate function?" Biochemical Pharmacology, vol. 66, no. 8, pp. 1555-1561, 2003.

[10] L. E. Finlan and T. R. Hupp, "p63: the phantom of the tumor suppressor," Cell Cycle, vol. 6, no. 9, pp. 1062-1071, 2007.

[11] A. Yang, M. Kaghad, Y. Wang et al., "p63, a p53 homolog at 3q27-29, encodes multiple products with transactivating, deathinducing, and dominant-negative activities," Molecular Cell, vol. 2, no. 3, pp. 305-316, 1998.

[12] F. Murray-Zmijewski, D. P. Lane, and J.-C. Bourdon, "p53/ p63/p73 isoforms: an orchestra of isoforms to harmonise cell differentiation and response to stress," Cell Death and Differentiation, vol. 13, no. 6, pp. 962-972, 2006.

[13] M. Mangiulli, A. Valletti, M. F. Caratozzolo et al., "Identification and functional characterization of two new transcriptional variants of the human p63 gene," Nucleic Acids Research, vol. 37, no. 18, pp. 6092-6104, 2009.

[14] H. van Bokhoven, B. C. J. Hamel, M. Bamshad et al., "p63 gene mutations in EEC syndrome, limb-mammary syndrome, and isolated split hand-split foot malformation suggest a genotypephenotype correlation," American Journal of Human Genetics, vol. 69, no. 3, pp. 481-492, 2001.

[15] A. A. Mills, B. Zheng, X.-J. Wang, H. Vogel, D. R. Roop, and A. Bradley, "p63 is a p53 homologue required for limb and epidermal morphogenesis," Nature, vol. 398, no. 6729, pp. 708713, 1999.

[16] A. Di Costanzo, L. Festa, O. Duverger et al., "Homeodomain protein Dlx3 induces phosphorylation-dependent p63 degradation," Cell Cycle, vol. 8, no. 8, pp. 1185-1195, 2009.

[17] K. E. King, R. M. Ponnamperuma, M. J. Gerdes et al., "Unique domain functions of p63 isotypes that differentially regulate distinct aspects of epidermal homeostasis," Carcinogenesis, vol. 27, no. 1, pp. 53-63, 2006.

[18] M. Paris, M. Rouleau, M. Pucéat, and D. Aberdam, "Regulation of skin aging and heart development by TAp63," Cell Death and Differentiation, vol. 19, no. 2, pp. 186-193, 2012.

[19] G. Wu, S. Nomoto, M. O. Hoque et al., “ $\Delta$ Np63 $\alpha$ and TAp63 $\alpha$ regulate transcription of genes with distinct biological functions in cancer and development," Cancer Research, vol. 63, no. 10, pp. 2351-2357, 2003.

[20] O. Gressner, T. Schilling, K. Lorenz et al., “TAp63 $\alpha$ induces apoptosis by activating signaling via death receptors and mitochondria," The EMBO Journal, vol. 24, no. 13, pp. 2458-2471, 2005.

[21] G. B. Deutsch, E. M. Zielonka, D. Coutandin et al., "DNA damage in oocytes induces a switch of the quality control factor TAp63 $\alpha$ from dimer to tetramer," Cell, vol. 144 , no. 4, pp. 566576, 2011.

[22] S. Gonfloni, L. Di Tella, S. Caldarola et al., "Inhibition of the c-Abl-TAp63 pathway protects mouse oocytes from chemotherapy-induced death," Nature Medicine, vol. 15, no. 10, pp. 1179-1185, 2009.

[23] G. B. Deutsch, E. M. Zielonka, D. Coutandin, and V. Dötsch, "Quality control in oocytes: domain-domain interactions regulate the activity of p63," Cell Cycle, vol. 10, no. 12, pp. 1884-1885, 2011. 
[24] X. Su, M. Paris, Y. J. Gi et al., "TAp63 prevents premature aging by promoting adult stem cell maintenance," Cell Stem Cell, vol. 5, no. 1, pp. 64-75, 2009.

[25] X. Su, Y. J. Gi, D. Chakravarti et al., "TAp63 is a master transcriptional regulator of lipid and glucose metabolism," Cell Metabolism, vol. 16, pp. 511-525, 2012.

[26] M. Rossi, R. I. Aqeilan, M. Neale et al., "The E3 ubiquitin ligase Itch controls the protein stability of p63," Proceedings of the National Academy of Sciences of the United States of America, vol. 103, no. 34, pp. 12753-12758, 2006.

[27] R.-A. Romano, K. Smalley, C. Magraw et al., “ $\Delta$ Np63 knockout mice reveal its indispensable role as a master regulator of epithelial development and differentiation," Development, vol. 139, no. 4, pp. 772-782, 2012.

[28] M. D. Westfall, D. J. Mays, J. C. Sniezek, and J. A. Pietenpol, “The $\Delta \mathrm{Np} 63 \alpha$ phosphoprotein binds the $\mathrm{p} 21$ and $14-3-3 \sigma$ promoters in vivo and has transcriptional repressor activity that is reduced by Hay-Wells syndrome-derived mutations," Molecular and Cellular Biology, vol. 23, no. 7, pp. 2264-2276, 2003.

[29] E. A. Ratovitski, M. Patturajan, K. Hibi, B. Trink, K. Yamaguchi, and D. Sidransky, "p53 associates with and targets $\Delta$ Np63 into a protein degradation pathway," Proceedings of the National Academy of Sciences of the United States of America, vol. 98, no. 4, pp. 1817-1822, 2001.

[30] J. Bergholz, Y. Zhang, J. Wu et al., " $\Delta$ Np63 $\alpha$ regulates Erk signaling via MKP3 to inhibit cancer metastasis," Oncogene, vol. 33, no. 2, pp. 212-224, 2012.

[31] R. A. Ihrie, M. R. Marques, B. T. Nguyen et al., "Perp is a p63regulated gene essential for epithelial integrity," Cell, vol. 120, no. 6, pp. 843-856, 2005.

[32] G. Wu, M. Osada, Z. Guo et al., " $\Delta \mathrm{Np} 63 \alpha$ up-regulates the Hsp70 gene in human cancer," Cancer Research, vol. 65, no. 3 , pp. 758-766, 2005.

[33] H. Ying, D. L. F. Chang, H. Zheng, F. McKeon, and Z.-X. J. Xiao, "DNA-binding and transactivation activities are essential for TAp63 protein degradation," Molecular and Cellular Biology, vol. 25, no. 14, pp. 6154-6164, 2005.

[34] Y. Okada, M. Osada, S.-I. Kurata et al., "p53 gene family p51(p63)-encoded, secondary transactivator p51b(TAp63 $\alpha$ ) occurs without forming an immunoprecipitable complex with MDM2, but responds to genotoxic stress by accumulation," Experimental Cell Research, vol. 276, no. 2, pp. 194-200, 2002.

[35] F. Galli, M. Rossi, Y. D’Alessandra et al., "MDM2 and Fbw7 cooperate to induce p63 protein degradation following DNA damage and cell differentiation," Journal of Cell Science, vol. 123, no. 14, pp. 2423-2433, 2010.

[36] J. Bakkers, M. Camacho-Carvajal, M. Nowak, C. Kramer, B. Danger, and M. Hammerschmidt, "Destabilization of $\Delta \mathrm{Np} 63 \alpha$ by Nedd4-mediated ubiquitination and Ubc9-mediated sumoylation, and its implications on dorsoventral patterning of the zebrafish embryo," Cell Cycle, vol. 4, no. 6, pp. 790-800, 2005.

[37] M. Rossi, M. De Simone, A. Pollice et al., "Itch/AIP4 associates with and promotes p63 protein degradation," Cell Cycle, vol. 5, no. 16, pp. 1816-1822, 2006.

[38] Y. J. Jeon, M. G. Jo, H. M. Yoo et al., "Chemosensitivity is controlled by p63 modification with ubiquitin-like protein ISG15," The Journal of Clinical Investigation, vol. 122, pp. 26222636, 2012.

[39] P. Ghioni, Y. D'Alessandra, G. Mansueto et al., "The protein stability and transcriptional activity of p63 $\alpha$ are regulated by SUMO-1 conjugation," Cell Cycle, vol. 4, no. 1, pp. 183-190, 2005.
[40] M. K. Leonard, N. T. Hill, E. D. Grant, and M. P. Kadakia, "DeltaNp63alpha represses nuclear translocation of PTEN by inhibition of NEDD4-1 in keratinocytes," Archives of Dermatological Research, vol. 305, pp. 733-739, 2013.

[41] M. Rossi, V. De Laurenzi, E. Munarriz et al., "The ubiquitinprotein ligase Itch regulates p73 stability," The EMBO Journal, vol. 24, no. 4, pp. 836-848, 2005.

[42] Y. Li, Z. Zhou, and C. Chen, "WW domain-containing E3 ubiquitin protein ligase 1 targets p63 transcription factor for ubiquitin-mediated proteasomal degradation and regulates apoptosis," Cell Death and Differentiation, vol. 15, no. 12, pp. 1941-1951, 2008.

[43] X. Li, J. Chen, Y. Yi, C. Li, and Y. Zhang, "DNA damage downregulates $\Delta \mathrm{Np} 63 \alpha$ and induces apoptosis independent of wild type p53," Biochemical and Biophysical Research Communications, vol. 423, no. 2, pp. 338-343, 2012.

[44] M. Dobbelstein, S. Wienzek, C. König, and J. Roth, "Inactivation of the p53-homologue p73 by the mdm2-oncoprotein," Oncogene, vol. 18, no. 12, pp. 2101-2106, 1999.

[45] X. Wang, T. Arooz, W. Y. Siu et al., "MDM2 and MDMX can interact differently with ARF and members of the p53 family," FEBS Letters, vol. 490, no. 3, pp. 202-208, 2001.

[46] V. Calabrò, G. Mansueto, T. Parisi, M. Vivo, R. A. Calogero, and G. L. Mantia, "The human MDM2 oncoprotein increases the transcriptional activity and the protein level of the p53 homolog p63," Journal of Biological Chemistry, vol. 277, no. 4, pp. 26742681, 2002

[47] Y. S. Jung, Y. Qian, W. Yan, and X. Chen, "Pirh2 E3 ubiquitin ligase modulates keratinocyte differentiation through p63," Journal of Investigative Dermatology, vol. 133, pp. 1178-1187, 2013.

[48] W. Yan, X. Chen, Y. Zhang, J. Zhang, and Y. S. Jung, "Arsenic suppresses cell survival via Pirh2-mediated proteasomal degradation of DeltaNp63 protein," The Journal of Biological Chemistry, vol. 288, pp. 2907-2913, 2013.

[49] Y. Huang, T. Sen, J. Nagpal et al., "ATM kinase is a master switch for the $\Delta \mathrm{Np} 63 \alpha$ phosphorylation/degradation in human head and neck squamous cell carcinoma cells upon DNA damage," Cell Cycle, vol. 7, no. 18, pp. 2846-2855, 2008.

[50] A. L. Craig, J. Holcakova, L. E. Finlan et al., “ $\Delta$ Np63 transcriptionally regulates ATM to control p53 Serine-15 phosphorylation," Molecular Cancer, vol. 9, article 195, 2010.

[51] M. MacPartlin, S. X. Zeng, and H. Lu, "Phosphorylation and stabilization of TAp $63 \gamma$ by I $\kappa$ B kinase- $\beta$," Journal of Biological Chemistry, vol. 283, no. 23, pp. 15754-15761, 2008.

[52] A. Chatterjee, X. Chang, T. Sen, R. Ravi, A. Bedi, and D. Sidransky, "Regulation of p53 family member isoform $\Delta \mathrm{Np} 63 \alpha$ by the nuclear factor- $\kappa \mathrm{B}$ targeting kinase $\mathrm{I} \kappa \mathrm{B}$ kinase $\beta$," Cancer Research, vol. 70, no. 4, pp. 1419-1429, 2010.

[53] G. D’Orazi, B. Cecchinelli, T. Bruno et al., "Homeodomaininteracting protein kinase-2 phosphorylates p53 at Ser 46 and mediates apoptosis," Nature Cell Biology, vol. 4, no. 1, pp. 11-20, 2002.

[54] T. G. Hofmann, A. Möller, H. Sirma et al., "Regulation of p53 activity by its interaction with homeodomain-interacting protein kinase-2," Nature Cell Biology, vol. 4, no. 1, pp. 1-10, 2002.

[55] C. Lazzari, A. Prodosmo, F. Siepi et al., "HIPK2 phosphorylates $\Delta \mathrm{np} 63 \alpha$ and promotes its degradation in response to DNA damage," Oncogene, vol. 30, no. 48, pp. 4802-4813, 2011.

[56] M. Simonatto, F. Marullo, F. Chiacchiera et al., "DNA damageactivated ABL-MyoD signaling contributes to DNA repair in skeletal myoblasts," Cell Death \& Disease, vol. 20, no. 12, pp. 1664-1674, 2013. 
[57] N. Reuven, J. Adler, V. Meltser, and Y. Shaul, "The Hippo pathway kinase Lats2 prevents DNA damage-induced apoptosis through inhibition of the tyrosine kinase c-Abl," Cell Death \& Disease, vol. 20, pp. 1330-1340, 2013.

[58] M. Yuan, P. Luong, C. Hudson, K. Gudmundsdottir, and S. Basu, "C-Abl phosphorylation of $\Delta \mathrm{np} 63 \alpha$ is critical for cell viability," Cell Death and Disease, vol. 1, no. 1, article e16, 2010.

[59] S. Komatsu, H. Takenobu, T. Ozaki et al., "Plk1 regulates liver tumor cell death by phosphorylation of TAp63," Oncogene, vol. 28, no. 41, pp. 3631-3641, 2009.

[60] J. Hildesheim, G. I. Belova, S. D. Tyner, X. Zhou, L. Vardanian, and A. J. Fornace Jr., "Gadd45a regulates matrix metalloproteinases by suppressing $\Delta \mathrm{Np} 63 \alpha$ and $\beta$-catenin via p38 MAP kinase and APC complex activation," Oncogene, vol. 23, no. 10, pp. 1829-1837, 2004.

[61] A. Fomenkov, R. Zangen, Y.-P. Huang et al., "RACK1 and stratifin target $\Delta \mathrm{Np} 63 \alpha$ for a proteasome degradation in head and neck squamous cell carcinoma cells upon DNA damage," Cell Cycle, vol. 3, no. 10, pp. 1285-1295, 2004.

[62] B. Serrels, E. Sandilands, A. Serrels et al., "A complex between FAK, RACK1, and PDE4D5 controls spreading initiation and cancer cell polarity," Current Biology, vol. 20, no. 12, pp. 10861092, 2010.

[63] M. Dohn, S. Zhang, and X. Chen, "p63 $\alpha$ and $\Delta \mathrm{Np} 63 \alpha$ can induce cell cycle arrest and apoptosis and differentially regulate p53 target genes," Oncogene, vol. 20, no. 25, pp. 3193-3205, 2001.

[64] Y. Li, M. J. Peart, and C. Prives, "Stxbp4 regulates $\Delta \mathrm{Np} 63$ stability by suppression of RACK1-dependent degradation," Molecular and Cellular Biology, vol. 29, no. 14, pp. 3953-3963, 2009.

[65] N. Wang, L. Guo, B. R. Rueda, and J. L. Tilly, “Cables1 protects p63 from proteasomal degradation to ensure deletion of cells after genotoxic stress," EMBO Reports, vol. 11, no. 8, pp. 633-639, 2010.

[66] F. Bernassola, A. Oberst, G. Melino, and P. P. Pandolfi, "The promyelocytic leukaemia protein tumour suppressor functions as a transcriptional regulator of p63," Oncogene, vol. 24, no. 46, pp. 6982-6986, 2005.

[67] C. Li, D. L. Chang, Z. Yang et al., "Pin1 modulates p63alpha protein stability in regulation of cell survival, proliferation and tumor formation," Cell Death \& Disease, vol. 4, p. e943, 2013.

[68] K. Nylander, B. Vojtesek, R. Nenutil et al., "Differential expression of p63 isoforms in normal tissues and neoplastic cells," Journal of Pathology, vol. 198, no. 4, pp. 417-427, 2002.

[69] M. Michaelis, F. Rothweiler, S. Barth et al., "Adaptation of cancer cells from different entities to the MDM2 inhibitor nutlin-3 results in the emergence of p53-mutated multi-drug-resistant cancer cells," Cell Death and Disease, vol. 2, no. 12, article e243, 2011. 

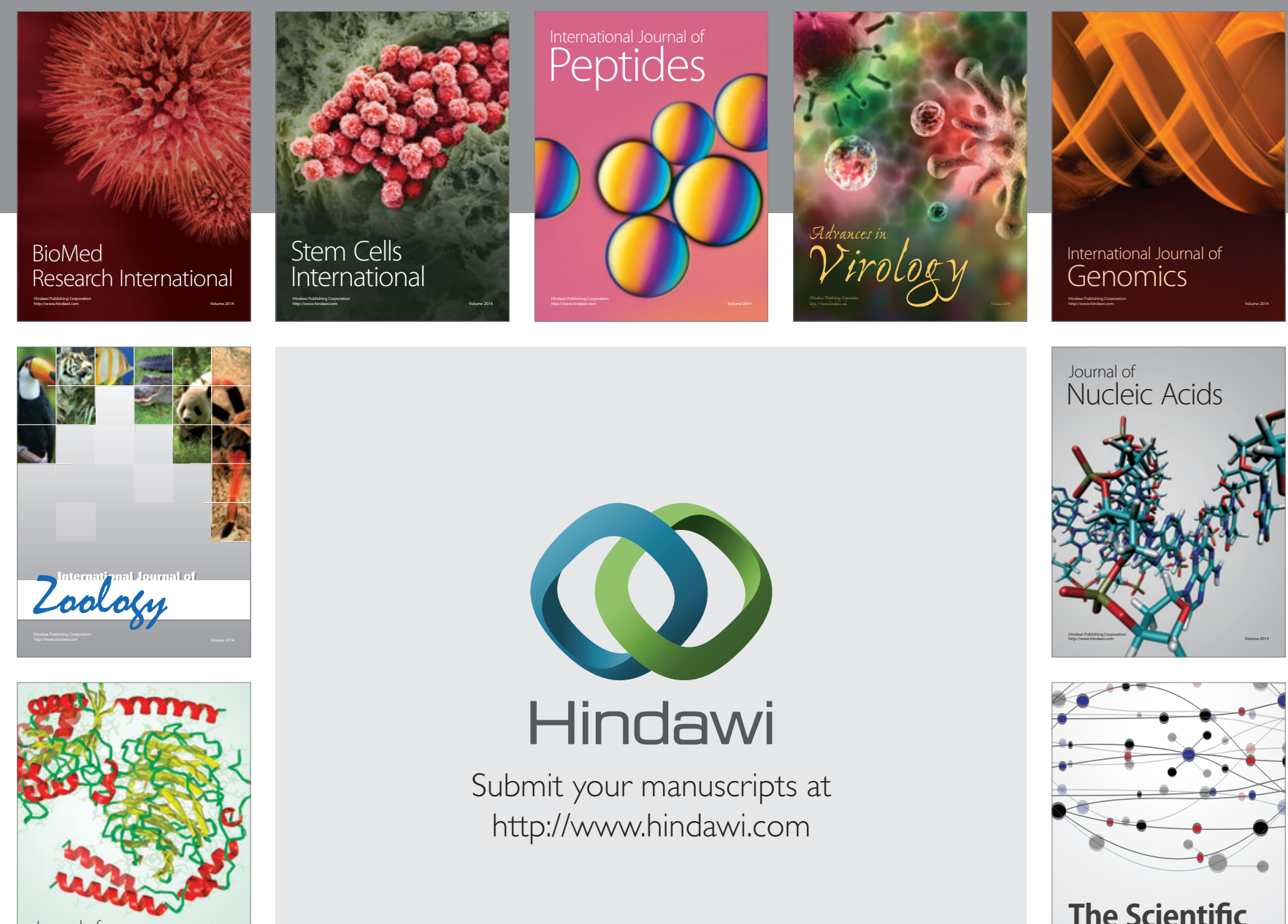

Submit your manuscripts at

http://www.hindawi.com

Journal of
Signal Transduction
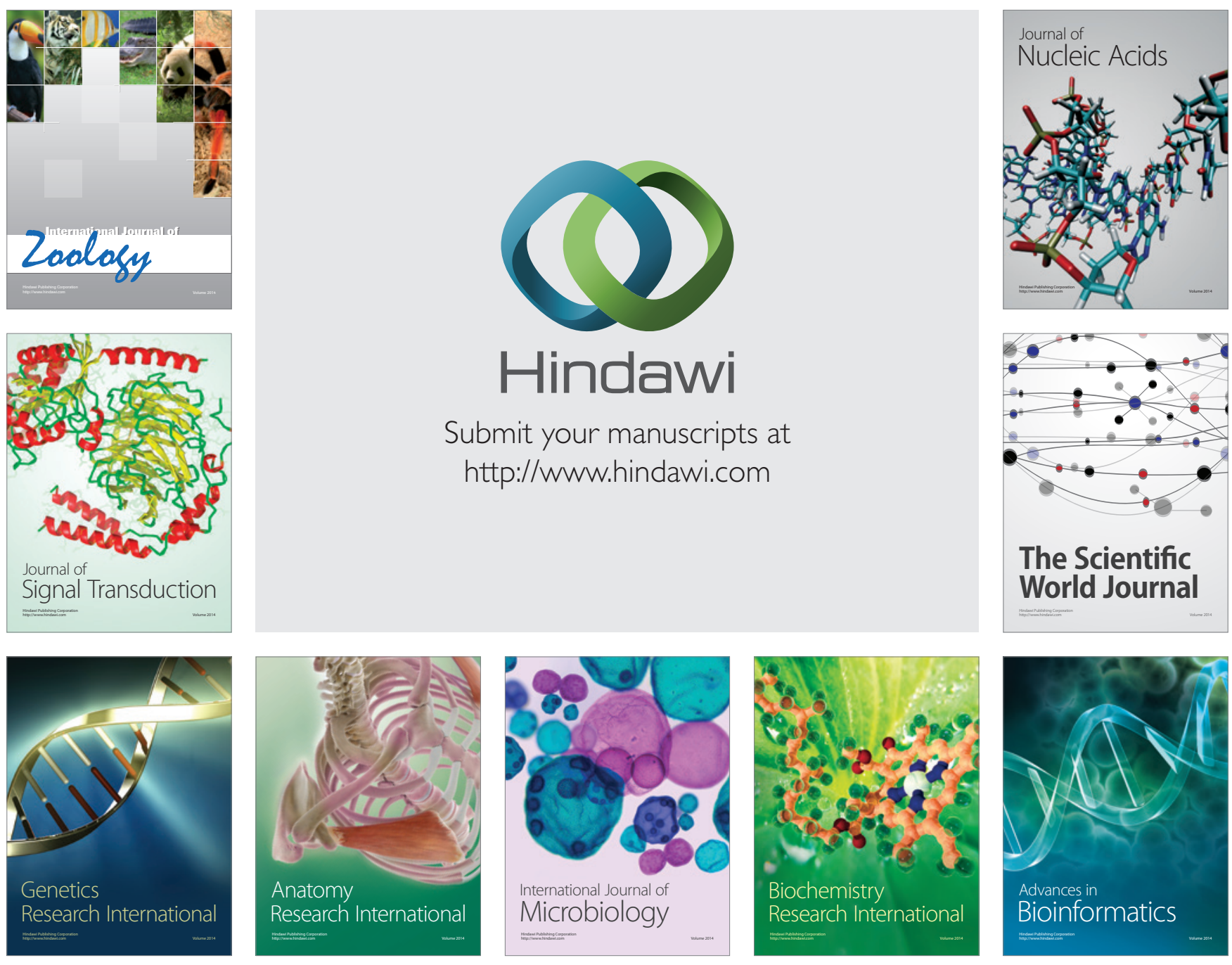

The Scientific World Journal
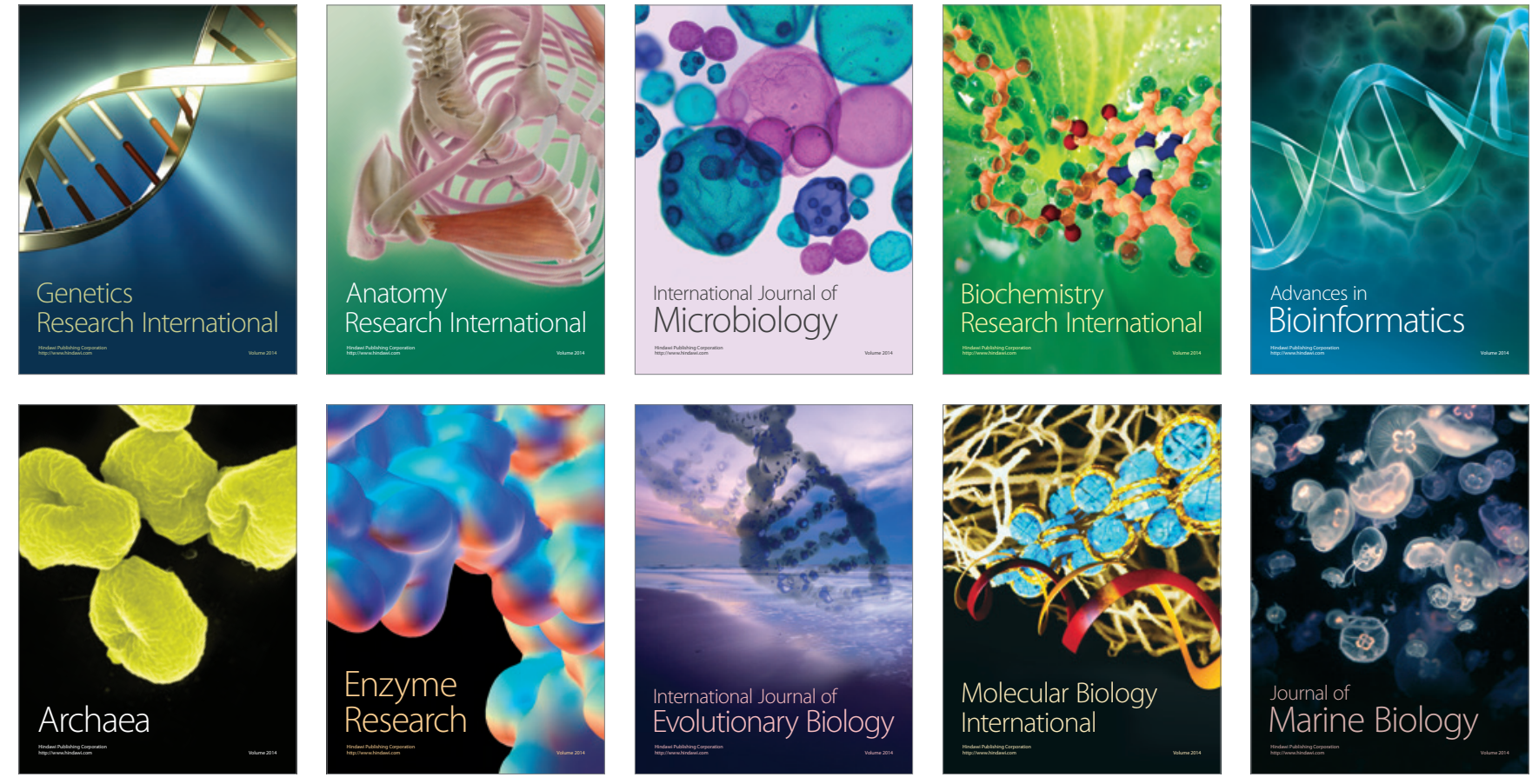